Psychological Medicine, 1983, 13, 479-481

Printed in Great Britain

\title{
EDITORIAL
}

\section{The idiot savant: flawed genius or clever Hans?}

Binet \& Simon (1909), although the originators of the concept of intelligence in its modern sense, nonetheless regarded it as a less unified function than did some of their Anglo-Saxon successors, such as Spearman (1927). Binet emphasized, for instance, the difference between perceptual intelligence and verbal ability, and also entertained a similar difference between sensory and scholastic abilities. The theory of a hierarchical structure of intelligence, based on the observed positive correlation of scores on tests of various cognitive functions, is a notion which is only implicit in Binet's discussions of intelligence for all that he used the word to describe a total state of mind. It is not inconsistent with his view therefore to find him referring to the 'idiot savant', i.e. an individual with one specific outstanding ability, but otherwise functioning on a low intellectual level (Binet, 1894).

Tredgold (1947), who was also aware of the phenomenon of the idiot savant, noted its predominant occurrence in males and remarked that such special abilities sometimes disappeared before adulthood, although this need not always be the case. Drawing and painting as well as many perceptual hypersensitivities are referred to by Tredgold, who mentions one patient who drew cats with such skill as to be described in 1768 as 'The Cats' Raphael'. George IV purchased one of the pictures of this gifted but severely mentally handicapped man. Many other cases are mentioned by Tredgold, including language imitators who can hardly speak spontaneously but can reproduce long statements in a number of languages, or recount arguments previously presented to them. But, although Tredgold notes that memory probably plays a part in such cases, he also observes that some such patients stand up well to cross-questioning. Langdon Down, who was responsible for the clinical identification of Down's Syndrome, was also one of the first to describe a calendrical calculator who could give the day of the week for any date over the five previous years. Other instances are on record of remarkable calculators capable of surprising feats of mental arithmetic, including the multiplication of three-figure numbers in a few seconds, the rapid calculation of square roots and the description of a geometric series to 64 places. Some more recent catalogues of individual cases have been collated by La Fontaine (1974), Duckett (1976), Hill (1978) and Rosen (1981).

From some such reports it might seem that the specific abilities of the idiot savant are not only outside the expected range of the capacities of the severely mentally handicapped, but are also above average normal competence. The issue is an important one for purposes of definition, and in our own project both kinds of level will be taken into account.

As far as incidence rates are concerned, Hill (1977) reports that $0.06 \%$ of the mentally retarded population in the USA who were in residential accommodation possessed a special or outstanding skill. He confirms that these skills themselves seem to be found in well-defined areas of behaviour, calendrical and arithmetical calculation ability being especially prominent. Outstanding memory, often confined to a specific subject-matter, and a talent for drawing, painting or music also occur.

Only a limited number of investigations have been concerned with the underlying mental processes for the specific skills shown by the idiot savant. Horwitz et al. (1965) proposed that rote memory was responsible for the ability to perform calendrical calculations and this view was also held by Hill (1978). Though Spitz \& La Fontaine (1973) reported forward digit spans ranging from 5 to 9 in a group of idiots savants, which was significantly longer than the spans of IQ-matched control subjects. Byrd (1920) and Mogridge \& Healy (1912) had previously reported spans of only 3-4 items. Duckett, in more recent and extensive investigations, found a mean span of 4.65 , a figure which so far concurs with our own limited study. But to explain the ability of the calendrical calculator,

' Address for correspondence: Dr B. Hermelin, IOE/MRC Developmental Psychology Project, 2 Taviton Street, London, W.C. 1. 
long-term rather than short-term memory should be thought to be relevant and, in addition, access to well above even 9 items in such long-term storage would have to be assumed.

Thus we are confronted here with a seemingly bizarre phenomenon, which cannot be easily incorporated into the current psychological and neuropsychological frameworks. From neither point of view can one easily envisage a mechanism, by which a congenital and diffuse cortical impairment, as is typically found in mental retardation, could nevertheless allow for the high level of development of a particular cognitive function or account for the sparing of the corresponding brain area.

However, there is another possible approach to the phenomenon of specific abilities, which is an extrapolation of one which we had previously taken in regard to specific deficits. In our own attempts to analyse and isolate possibly existing intelligence-independent cognitive functions, we began by comparing groups of autistic or retarded children, who sufferered from a general cognitive deficit, with children who had normal IQs, but a particular sensory impairment such as congenital blindness or deafness (O'Connor \& Hermelin, 1978). The underlying assumption for this set of experiments was that, in many instances, mental codes which are evoked do not seem to be extracted from current sensory stimulus input, but are based instead on stored memory images and representations derived from a different input modality.

The material used in our experiments was always directed towards an intact perceptual channel. However, the codes evoked by normal children were frequently not derived perceptually, but were instead based on mental representation. Blindfolded sighted children, for example, solved spatial problems by using visual images of tactually presented shapes. On the other hand, congenitally blind children had to rely on kinaesthetic information, and this tendency to use directly provided sensory rather than 'image' derived data was in many instances characteristic of autistic and subnormal children as well as the sensorily handicapped.

A similar paradigm was used in a set of studies with the generally and specifically gifted as distinct from the generally and specifically handicapped. Musically gifted children and children gifted for the visual arts were compared with controls, matched with them for IQ, as well as with children of very high general intelligence. In some verbal tasks the musically gifted proved to be equal to outstandingly intelligent children, despite a 20-point IQ difference. Similarly, artistically talented children showed superiority in comparison with an IQ matched control group in the perception of and memory for abstract shapes.

These experiments then seemed to us to indicate the existence of specific cognitive abilities which were not predictable from the general level of intelligence. The relevance of such an approach to the explanation of the idiot savant phenomenon is obvious, and there are two clear assumptions which could be tested. First, a specific ability, not predictable from general intellectual functioning, can occur at any level of intelligence. This conclusion, though not as yet having received any definite experimental confirmation, seems nevertheless well attested, not just through the occurrence of the idiot savant himself, but also from the biographies of many people with a variety of different talents whose general level of intelligence need certainly not be outstanding. Secondly, and more important in our present context, the existence of such specific abilities presupposes strategies in regard to certain mental processes which may be shared with other individuals of much higher general intelligence. In relation to the idiot savant, the task is thus to identify such processes and obtain some indications of the strategies used to achieve such high performance levels in restricted areas. In this context, account will also have to be taken of the way in which outstanding abilities are sometimes found among normal people. Hunter (1977) presented a case with an exceptional memory and compared his performance with that of a mnemonist described by Luria (1969). Both these men had by normal standards unusual memories, but Hunter points out that different strategies were used by them to achieve their high performance levels. It is possible that our own experiments may also show individual strategy differences between different idiots savants.

In a programme of research funded by the $\mathrm{MRC}$, we have identified and verified specific abilities in mentally retarded individuals, and have collected within a relatively short time 12 such cases. Our plan is to extend this group and then to carry out an appropriate series of experiments. 
The subjects so far identified are all drawn from hospitals for the mentally handicapped. Their ages range from 18 to 35 and their IQs, mostly measured on Wechsler Scales, from 30 to 75 . All but one are male. Seven are calculators, two being multipliers and five calendrical. Two others are artists, one is a musician, and one has a special knowledge of subjects such as the operation of nuclear power plants and arguments favouring bilateral nuclear disarmament. One Down's Syndrome patient writes notable poetic prose. The performance of ten of the twelve is at a level not usually achieved by normally intelligent people. Of the twelve, four are clearly autistic, one is probably psychotic and one obsessional. The performance of the pianist is remarkable for the outstanding auditory memory involved and, in addition, for the acquisition of a fingering technique which has never been taught but enables the patient to play Mozart and Beethoven. Although having little speech, he plays with expression. The patient with special areas of knowledge, which change from time to time, talks about his topics fluently with knowledge and concern. He is, however, unable or unwilling to talk about anything else and is untestable on standard tests.

The one controlled study which, as a first step in the project, we are conducting at the moment, investigates simple as well as choice visual reaction times in this group. There is convincing evidence that a strong relationship does exist between low IQ and long reaction time (Baumeister \& Kellas, 1968; Jensen, 1979; Vernon, 1981). As it is speed and efficiency of information processing that is measured by reaction time, it was thought possible that this relationship with measured intelligence might not be evident, or might exist to a lesser extent, in those individuals who possessed a specific high-level ability in spite of low IQ. However, first results indicate reaction times of a magnitude which would be consistent with the subject's measure of general low intelligence. Preliminary results also do not indicate unexpectedly long digit spans in this group. There will thus be a need for a more sophisticated conceptualization and more subtle and sensitive experimental procedures in order to elucidate the underlying mental processes and strategies which are responsible for the high performance in certain isolated skills by these 'idiots savants'.

\section{B. HER MELIN AND N. O'CONNOR}

\section{REFERENCES}

Baumeister, A. A. \& Kellas, G. (1968). Distribution of reaction times of retardates and normals. American Journal of Mental Deficiency 72, 715-718.

Binet, A. (1894). Psychologie des grandes calculateurs (et de jouers d'échecs). Hachette: Paris.

Binet, A. \& Simon, T. (1909). The intelligence of the feeble minded. L'Année Psychologique, pp. 15, 1-147.

Byrd, H. (1920). A case of phenomenal memorising in a feeble minded negro. Journal of Applied Psychology 4, 202-206.

Duckett, J. M. (1976). Savants: super specializations in mentally retarded persons. Unpublished Doctoral Dissertation: University of Texas, Austen.

Hill, A. L. (1977). Rate of incidence. Perceptual and Motor Skills 44, $161-162$.

Hill, A. L. (1978). Savants: mentally retarded individuals with special skills. In International Review of Research in Mental Retardation, Vol. 9 (ed. N. R. Ellis), pp. 277-298. Academic Press: New York.

Horwitz, W. A., Kestenbaum, C., Person, E. \& Jarvick, L. (1965). Identical twins - 'idiot savants' - calendar calculators. American Journal of Psychiatry 121, 1075-1079.
Hunter, J. M. L. (1977). An exceptional memory. British Journal of Psychology 68, 155-164.

Jensen, A. R. (1979). Reaction time, movement time, and intelligence. Intelligence 3, 121-126.

La Fontaine, L. (1974). Divergent abilities in the idiot savant. Unpublished Ed.D. thesis: Boston University School of Education.

Luria, A. R. (1969). The Mind of a Mnemonist. Jonathan Cape: London.

Mogridge, G. \& Healy, W. A. (1912). A feeble-minded genius. Journal of Psycho-Astenics 16, 93-102.

O'Connor, N. \& Hermelin, B. (1978). Seeing and Hearing and Space and Time. Academic Press: London.

Rosen, A. M. (1981). Adult calculators in a psychiatric OPD: A report of two cases and comparative analysis of abilities. Journal of Autism and Developmental Disorders 11, 285-292.

Spearman, C. (1927). The Nature of Intelligence and the Principles of Cognition. Macmillan: London.

Spitz, H. H. \& La Fontaine, L. (1973). The digit span of idiot savants. American Journal of Mental Deficiency 77, 757-759.

Tredgold, A. F. (1947). A Text Book of Mental Deficiency. Ballière, Tindall \& Cox: London.

Vernon, P. A. (1981). Reaction time and intelligence in the mentally retarded. Intelligence 5, 345-355. 